\title{
The Importance of A Good Sleep" (or Also of Why the Pope Should Learn to Give Habits to Their Children)
}

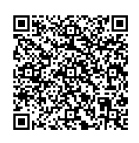

\author{
Miranda Nava Gabriel* \\ Neurologist and Clinical Neurophysiologist, Chief of Neurology of the Hospital Center of the Presidential General Staff, Mexico
}

Received: 紫 May 23, 2018; Published: 啙 May 29, 2018

*Corresponding author: Gabriel Miranda Nava, Neurologist and Clinical Neurophysiologist, Attached to the Hospital Center of the Presidential General Staff, Master in Public Health, Doctor in Administration and Public policies, Mexico

\section{Opinion}

Since we become parents at the same time we become a mirror of the potential actions that our children can carry out; do not be surprised when we see our children raving at very early stages when watching a football match when we do it religiously on each Sunday, with its respective repetition on cable TV, the summary in "action" or even the controversy in "the move". It also repeats the fact that to be drinkers or smokers our offspring by imitation do so with the typical conscience of "...if he can, why do not me ...?" And we believe that there is a genetic factor, which explains it, when the cry of the example is so strong that it silences the other voices of science.

The habit of sleep does not escape this destiny, but first of all I ask my kind and scarce readers to do a little exercise, find a child and ask him to pretend to sleep, you will find. That a child from small imitates the sound of snoring, a sign of orthodoxy in rest, without knowing that it is actually the prelude in older people of a chronic disease that leads to poor sleep and fragmented sleep. I write to you because I want to tell you about what is perhaps the best kept secret of public health problems in our country, sleeping sicknesses, which constitute a heterogeneous group of illnesses that directly, indirectly or circumstantially affect the way of sleeping in individuals. Among these diseases we find varied ailments, of different approach by the specialist doctor, with treatments that are adapted to each individual and a "tailored suit" of the needs of our patient is designed, but all, absolutely everyone will benefit from first instance to reinstate habits or sleep hygiene measures, which are a series of guidelines to improve the individual's relationship with the sleep-wake cycle (which is the day-night cycle) and which we will discuss later.

We found from the snorer, usually obese, some more with problems in the nose or in the rest of their upper airways, which is detested by partners or bed mates, night work because it causes a detrimental effect on the sleep of such people; there is a patient who loses sleep due to a depression or anxiety problem due to an economic conflict, a couple separation, change of address and other factors; there is the night watchman or the resident doctor who have altered the sleep wake cycle due to his work situation; the one who has been the victim of unscrupulous doctors who have prescribed them with sleeping pills for years without letting them know that, technically speaking, they are addicted; we also have that intercontinental traveller that causes the so-called "jet-lag" or less frequently that which is genetically predestined to sleep badly and in excess, those who suffer from narcolepsy, or in such common and badly identified problems as bruxism, which is when children rub or "carve" their teeth at night, with the equivocal differential diagnosis of "parasitosis". Each of the patients must be seen and approached in a very unique, personalized way and with the spirit of truly changing the life that they have up to now, that is, changing their quality of life, and that, requires a broad cooperation of the patient, is more about him than about the doctor himself, and that's where the difference between one patient and another lies.

But what we should always understand is that we should try to inherit good habits from our children, including sleep; in my clinic it is typical that the school-aged child misdiagnosed as having a disorder due to attention deficit and hyperactivity, treated with stimulant drugs, call it Ritalin, then I ask a magical question at what time does this child sleep?? Always precedes the response a halo of shame and mortification, because they prevent the scolding and attention call reflects the fact that thanks to video games, cable TV, even cell phones lengthen the onset of sleep and thus, shorten their times of bed as well as sleep, with the usual disruption in their neurotransmitters resulting in a poor diurnal response, seen in poor school performance, irritability and mood changes, preterits of depression and anxiety.

Throughout our deliveries we will mention and discuss various medical conditions of public interest, and we will debut with sleep disorders. 
(c) This work is licensed under Creative

To Submit Your Article Click Here: Submit Article

DOI: $10.32474 / 0 J N B D .2018 .01 .000112$

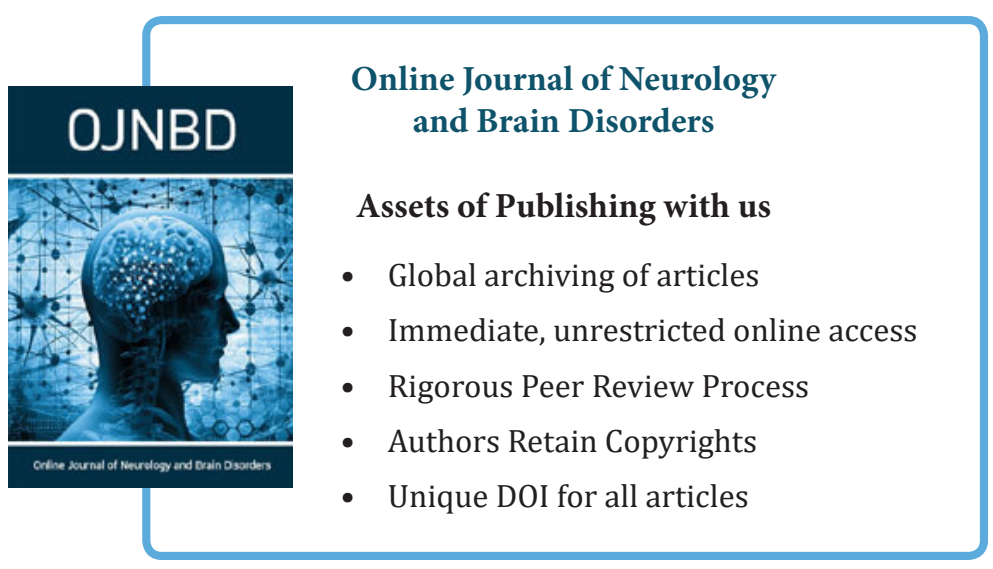

